\title{
A rare case of acute motor axonal neuropathy and myelitis related to SARS-CoV-2 infection
}

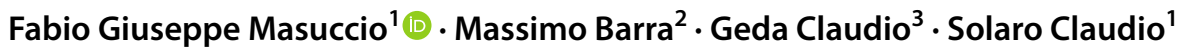

Received: 7 July 2020 / Revised: 1 September 2020 / Accepted: 3 September 2020 / Published online: 17 September 2020

c) Springer-Verlag GmbH Germany, part of Springer Nature 2020

\begin{abstract}
We describe a rare case of post-infective Acute Motor Axonal Neuropathy (AMAN) variant of Guillain-Barrè Syndrome (GBS) associated with myelitis and anti-GD1b positivity after SARS-CoV-2 infection. The patient referred to the hospital reporting a history of ten days lasting moderate fever, myalgia and anosmia, with the onset of progressive quadriparesis and ascending paraesthesias in the four limbs since five days from defervescence. A chest computed tomography demonstrated interstitial pneumonia with "ground glass opacities", suggesting Coronavirus disease (COVID-19). The patient exhibited three negative reverse-transcription polymerase chain reaction (RT-PCR) nasopharyngeal swabs, while SARS-CoV-2 IgG was found in plasma. The electrophysiological examination demonstrated an AMAN and the spinal cord Magnetic Resonance Imaging (MRI) showed a T2-weighted hyperintense lesion in the posterior part of the spinal cord at the C7-D1 levels. Furthermore, anti-GD1b IgM was detected. GBS and myelitis could exceptionally develop simultaneously. Our findings reasonably support a causality link between COVID-19 and the neurological symptoms, suggesting a post-infective autoimmune reaction.
\end{abstract}

Keywords SARS-CoV-2 $\cdot$ Guillain-barrè syndrome $\cdot$ Myelitis $\cdot$ AMAN $\cdot$ Antiganglioside antibodies

\section{Dear Sirs,}

The recent pandemy of severe acute respiratory syndrome coronavirus 2 (SARS-CoV-2) challenged the sanitary systems worldwide, not only for the prominent respiratory features, but also for the neurological complications involving both the central and the peripheral nervous system, the evidence of which is continuously rising [1].

We describe a case of post-infective Acute Motor Axonal Neuropathy (AMAN) variant of Guillain-Barrè Syndrome (GBS) associated with myelitis and anti-GD1b antibodies positivity after SARS-CoV-2 infection.

A 70-year-old Caucasian woman affected with obesity and hypertension reported a history of 10 days lasting

Fabio Giuseppe Masuccio

fgmasuccio@yahoo.it

1 Department of Neurorehabilitation, C.R.R.F. "Mons. L. Novarese", Loc. Trompone, SNC, 13040 Moncrivello, VC, Italy

2 Department of Neurology, ASL TO4 Chivasso, C.so G. Ferraris 3, Chivasso, Italy

3 Department of Neurology, ASL TO4 Ivrea, P.za Credenza 2, Ivrea, Italy moderate fever (with maximum temperature of $38^{\circ} \mathrm{C}$ ), anosmia and generalized myalgia. After 5 days from defervescence, she experienced progressive difficulties in walking with ascending paraesthesias in the four limbs. Ten days later, she referred to the Chivasso Hospital, Piedmont, Italy, being bedridden.

At admission in the emergency department, the patient presented no fever and an oxygen saturation of $96 \%$ on room air. The laboratory results revealed a moderately raised C-reactive protein and a moderate lymphocytopenia with normal neutrophils count, not associated with heart, liver or kidney alterations. The patient was promptly tested with a first reverse transcription-polymerase chain reaction (RTPCR) nasopharyngeal swab, which was negative.

The neurological examination showed a picture of severe quadriparesis, with reduced strength in the upper limbs [Medical Research Council (MRC) score 3/5] and flaccid paralysis of the lower limbs (MRC score 0/5). A decreased tactile and pain sensation in the lower limbs accompanied with urinary retention and perineal areflexia were observed. In addition, deep tendon reflexes were increased in the four limbs and a bilateral Babinski sign was evocable. Brainstem and cortical functions were preserved. 
In consideration of the patient history, a chest computed tomography scan (CT-scan) was performed and documented an interstitial pneumonia with "ground glass" opacities, suggestive for Coronavirus disease (COVID-19). Thus, other two RT-PCR nasopharyngeal swabs were performed on day 2 and 15 , however with negative results.

The analysis of the cerebrospinal fluid (CSF) showed normal levels of protein and cells and an oligoclonal band mirror pattern was found. The screening for Epstein-Barr Virus, Cytomegalovirus, Herpes Simplex Virus and Herpes Zoster Virus, HIV, Borrelia Burgdorferi, Chlamidya and Mycoplasma Pnaeumoniae was negative for IgM and IgG on serum and on the CSF. In contrast, SARS-CoV-2 IgG were determined and detected in the plasma after 30 days from the onset of COVID-19 symptoms. In this regard, it has to be noted that the patient referred to the hospital 25 days after fever onset.

Amongst antiganglioside antibodies, anti-GD1b IgM were identified in the serum.

The electrophysiological examination (Table 1), performed the day after the admission, was indicative of an AMAN $[2,3]$. In particular, in the four limbs, motor and sensory conduction velocities were normal and no blocks of conduction were found also in Erb and axilla stimulation,

Table 1 Electrophysiological characteristics in the four limbs (initial and follow-up evaluation)

\begin{tabular}{|c|c|c|c|c|}
\hline Nerve conductions & $\begin{array}{l}\text { Distal Latency (ms) } \\
\text { FE/FU }\end{array}$ & $\begin{array}{l}\text { Amplitude (mV) } \\
\text { FE/FU }\end{array}$ & $\begin{array}{l}\text { Conduction velocity }(\mathrm{m} / \mathrm{s}) \\
\text { FE/FU }\end{array}$ & $\begin{array}{l}\text { F-waves latency (ms) } \\
\text { FE/FU }\end{array}$ \\
\hline \multicolumn{5}{|l|}{ Motor } \\
\hline \multicolumn{5}{|l|}{ Median nerve } \\
\hline $\begin{array}{l}\text { Wrist-abductor pollicis } \\
\text { brevis }\end{array}$ & $\mathrm{L}=4.99 / 4.19 ; \mathrm{R}=4.00 / 4.19$ & $\begin{array}{l}\mathrm{L}=12.73 / 10.56 \\
\mathrm{R}=10.85 / 12.28\end{array}$ & & $\begin{array}{l}\mathrm{L}=30.73 / 28.47 \\
\mathrm{R}=29.84 / 28.78\end{array}$ \\
\hline Below elbow-wrist & $\mathrm{L}=9.51 / 8.97 ; \mathrm{R}=9.29 / 8.86$ & $\begin{array}{l}\mathrm{L}=13.01 / 8.63 \\
\mathrm{R}=13.95 / 12.22\end{array}$ & $\begin{array}{l}\mathrm{L}=50.98 / 52.30 \\
\mathrm{R}=51.60 / 51.37\end{array}$ & $*(\mathrm{NV} \leq 27.5)$ \\
\hline \multicolumn{5}{|l|}{ Ulnar nerve } \\
\hline $\begin{array}{l}\text { Wrist-abductor digiti } \\
\text { minimi }\end{array}$ & $\mathrm{L}=2.87 / 2.69 ; \mathrm{R}=2.86 / 2.30$ & $\begin{array}{l}\mathrm{L}=15.22 / 15.21 \\
\mathrm{R}=20.87 / 18.88\end{array}$ & $\mathrm{~L}=51.58 / \mathrm{NA} ; \mathrm{R}=51.26 / \mathrm{NA}$ & $\begin{array}{c}\mathrm{L}=29.61 / 27.01 \\
\mathrm{R}=28.14 / 26.52\end{array}$ \\
\hline Below elbow-wrist & $\mathrm{L}=7.24 / 7.01 ; \mathrm{R}=6.96 / 6.90$ & $\begin{array}{l}\mathrm{L}=12.97 / 11.74 \\
\mathrm{R}=16.83 / 15.35\end{array}$ & $\begin{array}{c}\mathrm{L}=59.40 / 66.99 \\
\mathrm{R}=59.40 / 65.20\end{array}$ & $*(\mathrm{NV} \leq 28.5)$ \\
\hline Over-below elbow & $\mathrm{L}=8.42 ; \mathrm{R}=8.14$ & $\mathrm{~L}=12.12 ; \mathrm{R}=19.25$ & & \\
\hline \multicolumn{5}{|l|}{ Tibial nerve } \\
\hline $\begin{array}{l}\text { Med. malleolus-abd. } \\
\text { hallucis b }\end{array}$ & $\mathrm{L}=5.29 / 5.29 ; \mathrm{R}=4.11 / 4.27$ & $\mathrm{~L}=3.59 / 5.11 ; \mathrm{R}=5.69 / 4.27$ & & $\begin{array}{l}\mathrm{L}=56.84 / \mathrm{A} \\
\mathrm{R}=52.77 / 53.76\end{array}$ \\
\hline $\begin{array}{l}\text { Popliteal fossa-med. } \\
\text { malleolus }\end{array}$ & $\begin{array}{l}\mathrm{L}=13.84 / 14.74 \\
\mathrm{R}=13.44 / 14.68\end{array}$ & $\mathrm{~L}=4.65 / 3.94 ; \mathrm{R}=4.27 / 1.72$ & $\begin{array}{c}\mathrm{L}=46.79 / 42.33 \\
\mathrm{R}=48.20 / 40.37\end{array}$ & $*(\mathrm{NV} \leq 49)$ \\
\hline \multicolumn{5}{|l|}{ Peroneal Nerve } \\
\hline $\begin{array}{l}\text { Ankle-extensor digit. } \\
\text { Brevis }\end{array}$ & $\mathrm{L}=3.54 / 3.43 ; \mathrm{R}=3.26 / 2.87$ & $\mathrm{~L}=3.17 / 3.10 ; \mathrm{R}=1.09 / 2.33$ & & $\begin{array}{c}\mathrm{L}=53.17 / 48.83 \\
\mathrm{R}=\mathrm{A} / 49.18\end{array}$ \\
\hline Caput fibulae-ankle & $\begin{array}{l}\mathrm{L}=10.80 / 11.47 \\
\mathrm{R}=10.63 / 10.63\end{array}$ & $\mathrm{~L}=2.74 / 2.21 ; \mathrm{R}=0.78 / 1.89$ & $\begin{array}{l}\mathrm{L}=48.24 / 42.27 \\
\mathrm{R}=50.80 / 43.81\end{array}$ & $*(\mathrm{NV} \leq 49.5)$ \\
\hline $\begin{array}{l}\text { Popliteal fossa- Caput } \\
\text { fibulae }\end{array}$ & $\begin{array}{l}\mathrm{L}=12.77 / 12.60 \\
\mathrm{R}=12.15 / 11.92\end{array}$ & $\mathrm{~L}=2.59 / 2.37 ; \mathrm{R}=0.58 / 1.16$ & $\begin{array}{l}\mathrm{L}=48.86 / 44.45 \\
\mathrm{R}=46.10 / 46.38\end{array}$ & \\
\hline \multicolumn{5}{|l|}{ Antidromic sensory } \\
\hline \multicolumn{5}{|l|}{ Median nerve } \\
\hline Wrist-II finger & $\mathrm{L}=3.85 / 3.08 ; \mathrm{R}=3.49 / 2.75$ & $\begin{array}{c}\mathrm{L}=23.57 / 36.86 \\
\mathrm{R}=43.16 / 33.81\end{array}$ & $\begin{array}{c}\mathrm{L}=38.94 / 51.91 \\
\mathrm{R}=40.09 / 50.97\end{array}$ & \\
\hline \multicolumn{5}{|l|}{ Ulnar nerve } \\
\hline Wrist-IV finger & $\mathrm{L}=2.43 / 2.22 ; \mathrm{R}=3.49 / 1.92$ & $\begin{array}{l}\mathrm{L}=70.48 / 75.45 \\
\mathrm{R}=39.67 / 108.66\end{array}$ & $\begin{array}{l}\mathrm{L}=53.41 / 58.50 \\
\mathrm{R}=58.45 / 62.42\end{array}$ & \\
\hline \multicolumn{5}{|l|}{ Radial nerve } \\
\hline Wrist-I finger & $\mathrm{L}=2.62 / 1.63 ; \mathrm{R}=1.74 / 1.90$ & $\begin{array}{l}\mathrm{L}=35.35 / 27.81 \\
\mathrm{R}=38.75 / 34.94\end{array}$ & $\begin{array}{l}\mathrm{L}=51.44 / 61.36 \\
\mathrm{R}=57.49 / 63.00\end{array}$ & \\
\hline \multicolumn{5}{|l|}{ Sural nerve } \\
\hline Calf-Lat. malleolus & $\mathrm{L}=1.82 / 2.10 ; \mathrm{R}=1.50 / 1.37$ & $\begin{array}{l}\mathrm{L}=12.06 / 14.51 \\
\mathrm{R}=11.07 / 32.25\end{array}$ & $\begin{array}{l}\mathrm{L}=54.88 / 57.12 \\
\mathrm{R}=53.31 / 58.31\end{array}$ & \\
\hline
\end{tabular}

L, left; R, right; A, absent; *NV, normal values for F-waves latency; FE/FU, first evaluation/follow-up; NA, not available 
while a reduction of motor amplitude was detected. In lower limbs, a mild increase in distal latencies and a bilateral impairment of $\mathrm{F}$-waves were present. The axonopathic features were confirmed in the follow-up electrophysiological examination, conducted after 6 weeks (see Table 1 for further details).

Magnetic Resonance Imaging (MRI) showed no lesions in brain, whereas it demonstrated an area of hyperintensity in T2-weighted sequences in the posterior portion of the spinal cord. This area had a cylindrical shape in the sagittal view and encompassed two vertebral levels (C7-D1), without T1-weighted hypointensity and inflammatory activity after gadolinium administration (Fig. 1). A follow-up spinal cord MRI, performed five days later, showed no differences in the cervical lesion and no other lesion neither in the thoracic nor in the lumbar segments.

The patient underwent plasma exchange followed by one course of intravenous immunoglobulins, partially recovering the strength in the upper limbs. However, after 40 days from the onset of COVID-19 symptoms, a severe paraparesis (MRC 1/5) and perineal areflexia persist. At the present time, the person is sustaining rehabilitation for the recovery of autonomy in the everyday life activities.

Although exceptionally, GBS and myelitis could develop simultaneously [4]. This occurrence represents an intriguing challenge for the clinicians, due to the presentation of both central and peripheral neurological symptoms and signs. With this respect, the electrophysiological examination and MRI play a crucial role to reach a diagnosis [4].

Some cases of GBS related to SARS-CoV-2 infection have been reported [5-8]. However, to the best of our knowledge, in only one case antiganglioside antibodies positivity
(anti-GD1a) was found [7], while none reported a concomitant myelitis.

According to these cases, it might be possible that SARSCoV-2-related GBS might manifest not only as a post-infective disease, in agreement with the classical GBS presentation, but also as a para-infective manifestation [6], probably owing to a direct viral effect [9].

In our rare case, the time elapsed between fever onset and the neurological symptoms, i.e. 15 days, associated with the presence of SARS-CoV2 IgG and anti-GD1b IgM, might reasonably advocate for a SARS-CoV-2-related acute AMAN/myelitis complex, as a result of a post-infective autoimmune reaction mechanism.

It might be argued that a possible limitation might be the absence of positive RT-PCR nasopharyngeal swabs. Nevertheless, it has to be noted that the patient referred to the hospital after 25 days from the start of COVID-19 symptoms, that a chest CT-scan documented interstitial pneumonia compatible with COVID-19 and that SARS-CoV-2 IgG were found, possibly indicating that seroconversion had happened and that the virus had been probably already eliminated. Besides, the presence of antiganglioside antibodies might suggest that an autoimmune reaction has interested the nervous system.

With this respect, the positivity of the anti-GD1b IgM is reported to be associated to several immune-mediated neuropathies, such as Chronic Ataxic Neuropathy Ophthalmoplegia IgM paraprotein Cold Agglutinins Disialosyl antibodies (CANOMAD) and Chronic Ataxic Neuropathy with Disialosyl Antibodies (CANDA), while in AMAN anti-GD1b IgG are more frequently detected [10]. In our case, an electrophysiological picture suggestive of AMAN
Fig. 1 MRI of the spinal cord; on the left, a cylindrically shaped hyperintense lesion encompassing the C7-D1 levels in the sagittal view; on the right, the same lesion in two axial views

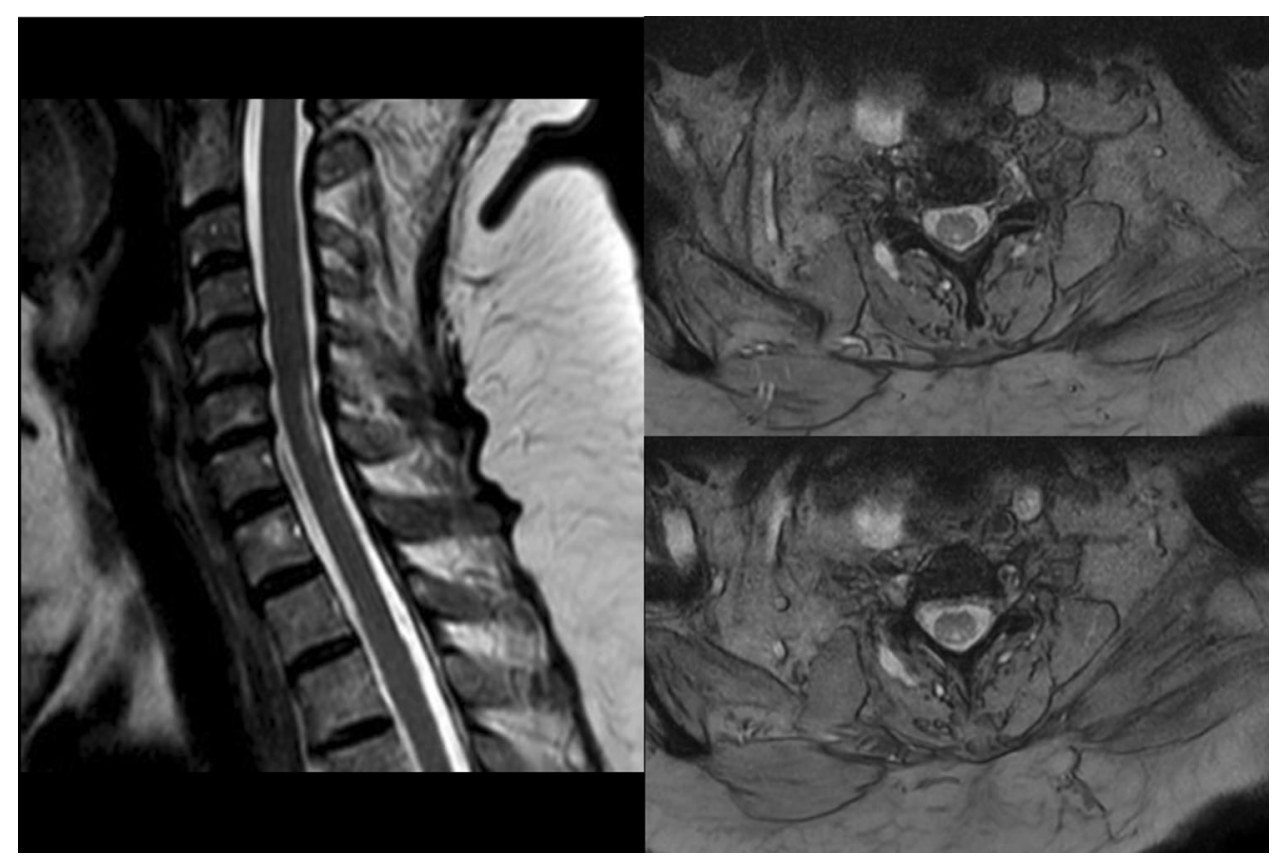


and anti-GD1b IgM coexist. We are aware of this ostensible inconsistency, however, being this a single case, a clear explanation cannot be provided and needs to be further investigated. Namely, GD1b is located in the dorsal root ganglion cells and in paranodal myelin and is associated with the presence of sensory disturbances [11].

When reflecting on our case and on the cases in the Italian population $[5,7,8]$, the hypothesis arises that an axonal involvement might be more frequent in GBS related to SARS-CoV-2 infection, in comparison with the typical AMAN prevalence in the European population [2]. However, it is not possible to infer definitive deductions due to the small number of cases registered.

The lesson learned in this outbreak of SARS-CoV-2 is that the neurological manifestations attributable to COVID19 are not so uncommon and should not be underestimated. Nowadays, too few data are available on these neurological alterations and it appears a matter of crucial interest that the clinicians pay attention to them as they might have rare presentations, as in our case. In this regard, further studies should be addressed to the comprehension of the real prevalence and possibly to the pathogenesis of these conditions.

Funding Not applicable.

Data availability Anonymized data and material regarding this case report not included in the manuscript are available on request to the corresponding author by any qualified investigator.

\section{Compliance with ethical standards}

Conflicts of interest The authors declare no conflict of interest relevant to this paper.

Ethical standard Patient's informed consent and permission to publish her information have been obtained.

Informed Consent Written informed consent was collected from the patient for the inclusion of anonymized clinical data in a scientific publication, in agreement with the Declaration of Helsinki.

\section{References}

1. Wang L, Shen Y, Li M et al (2020) Clinical manifestations and evidence of neurological involvement in 2019 novel coronavirus SARS-CoV-2: a systematic review and meta-analysis. J Neurol. https://doi.org/10.1007/s00415-020-09974-2

2. Willison HJ, Jacobs BC, van Doorn PA (2016) Guillain-Barré syndrome. Lancet 388:717-727. https://doi.org/10.1016/S0140 -6736(16)00339-1

3. Hadden RDM, Cornblath DR, Hughes RAC et al (1998) Electrophysiological classification of Guillain-Barre syndrome: clinical associations and outcome. Ann Neurol 44:780-788. https://doi. org/10.1002/ana.410440512

4. Guo F, Zhang YB (2019) Clinical features and prognosis of patients with Guillain-Barré and acute transverse myelitis overlap syndrome. Clin Neurol Neurosurg 181:127-132. https://doi. org/10.1016/j.clineuro.2019.04.014

5. Toscano G, Palmerini F, Ravaglia S et al (2020) GuillainBarré Syndrome Associated with SARS-CoV-2. N Engl J Med NEJMc2009191. https://doi.org/10.1056/NEJMc2009191

6. Zhao H, Shen D, Zhou H et al (2020) Guillain-Barré syndrome associated with SARS-CoV-2 infection: causality or coincidence? Lancet Neurol 19:383-384. https://doi.org/10.1016/S1474 -4422(20)30109-5

7. Padroni M, Mastrangelo V, Asioli GM et al (2020) Guillain-Barré syndrome following COVID-19: new infection, old complication? J Neurol. https://doi.org/10.1007/s00415-020-09849-6

8. Riva N, Russo T, Falzone YM et al (2020) Post-infectious Guillain-Barré syndrome related to SARS-CoV-2 infection: a case report. J Neurol 267:2492-2494. https://doi.org/10.1007/s0041 5-020-09907-Z

9. Zhou Z, Kang H, Li S, Zhao X (2020) Understanding the neurotropic characteristics of SARS-CoV-2: from neurological manifestations of COVID-19 to potential neurotropic mechanisms. J Neurol. https://doi.org/10.1007/s00415-020-09929-7

10. Yuki N, Uncini A (2014) Acute and chronic ataxic neuropathies with disialosyl antibodies: a continuous clinical spectrum and a common pathophysiological mechanism. Muscle Nerve 49:629635. https://doi.org/10.1002/mus.24192

11. Taams NE, Notermans NC, Fokkink WJR et al (2018) Clinical relevance of serum antibodies to GD1b in immune-mediated neuropathies. J Peripher Nerv Syst 23:227-234. https://doi. org/10.1111/jns. 12285 